\title{
SUPRAGLOTIIC AIRWAY DEVICES AS A METHOD OF AIRWAY MANAGEMENT IN PREHOSPITAL SETTING
}

\author{
Marcin Madziala
}

Lazarski University, Warsaw, Poland

Disaster Emerg Med J 2019; 4(1): 29-30

To the Editor,

It was with great interest and enthusiasm that I read the article "CombiTube during cardiopulmonary resuscitation" by Michael Frass et al. Modern emergency medicine aims to optimize the principles of cardiopulmonary resuscitation, taking into account the most professional treatment at each stage of assistance from first aid through qualified first aid to emergency medical services [1]. Firefighters are the leading rescue service in Poland and are often the first to undertake activities in the field of qualified first aid, including in particular cardiopulmonary resuscitation, and operate in a zone to which medical personnel has no access due to present danger [2]. The high quality of performed resuscitation not only focuses on activities related to chest compressions and, when needed, defibrillation, but also the proper protection of airways and adequate ventilation. Emphasis is placed on tracheal intubation or supraglottic device incorporation without interrupting chest compressions [3, 4].

In their study, the authors demonstrated that the average time of protection of airways by firefighters using the CombiTube device without chest compressions and with chest compressions was respectively: $21 \mathrm{~s}(\mathrm{IQR}, 14-25.5)$ against $21.5 \mathrm{~s}$ (IQR; 15-27). $A$ vast number of attempts of placing the CombiTube was successful and positioned in the oesophagus: 92.8\%. 91.1\% (with chest compressions or without). Participants of the study assessed the ease of performing the procedure at 19 points (IQR, 13-22) for a chest-free scenario and 18.5 points (IQR, 14-21,5) for a situation with uninterrupted chest compressions [5]. This serves as a confirmation to many studies which similarly indicated the ease of using supraglottic devices after a short instruction [6].

Currently, as a part of first aid certification, firefighters are authorized to use supraglottic methods of airway clearance after completing a 66-hour course in this field. The methods used by them, in addition to standard CPR, also include activities related to the use of supraglottic devices to ensure airway patency, including the use of CombiTube. Tracheal intubation is reserved for medical personnel; it is an excellent alternative that increases the effectiveness of assisted ventilation in people during cardiopulmonary resuscitation performed by firefighters. Until now, the only device acceptable for use as an oropharyngeal tube; however, it is not identical to the CombiTube ventilation. During my work as a Municipal Medical Rescue Coordinator of the State Fire Service, I have dealt many times with situations in which officers of the State Fire Service and members of the Volunteer Fire Brigade used supraglottic methods of maintaining airway patency. Confirming the quoted article, after a short training they can do it in simulated conditions, and then apply this method during real events, in the case of victims of sudden cardiac arrest, including injured people, most often in situations of communication incidents, i.e. where a degree of injury prescribes suspicion of damage to the cervical spine [7].

The lack of skills and legal limitations for firefighters to perform tracheal intubation while the everyday situations require them to assess/clear airway in suspicion of an injury to the cervical spine makes the described method of airway patency rescue entirely approved among firefighters. It is also 
imperative that the establishment of CombiTube does not require firefighters to stop compressing the chest, hence the effectiveness of resuscitation becomes greater, which is entirely a reflection of the current recommendations for resuscitation [8]. The CombiTube is a device that after installation allows for asynchronous ventilation, and its standardized connector also allows the use of a colorimetric capnometer which in turn enables to verify breathing by people with spontaneous breath, e.g., after effective resuscitation [9]. Contraindications to the use of CombiTube are injuries in the lower part of the throat and larynx [10].

\section{REFERENCES}

1. Qara FJ, Alsulimani LK, Fakeeh MM, et al. Knowledge of Nonmedical Individuals about Cardiopulmonary Resuscitation in Case of Cardiac Arrest: A Cross-Sectional Study in the Population of Jeddah, Saudi Arabia. Emerg Med Int. 2019; 2019: 3686202, doi: 10.1155/2019/3686202, indexed in Pubmed: 30792927.

2. Kasinski M, Madziala M, Iskrzycki L, et al. Are firefighters able to perform blind endotracheal intubation via LMA Fastrach? An experimental study. Am J Emerg Med. 2016; 34(12): 2458-2459, doi: 10.1016/j. ajem.2016.09.035, indexed in Pubmed: 27743626.

3. Ruetzler K, Leung $S$, Chmiela M, et al. Regurgitation and pulmonary aspiration during cardio-pulmonary resuscitation (CPR) with a laryngeal tube: A pilot crossover human cadaver study. PLoS One. 2019;
14(2): e0212704, doi: 10.1371/journal.pone.0212704, indexed in Pubmed: 30811470.

4. Blanco J, Madziala M, Szalast P. Which chest compression technique is more fatiguing for rescuer? Disaster and Emergency Medicine Journal. 2018; 3(4): 150-151, doi: 10.5603/DEMJ.2018.0031.

5. Frass $M$, Robak 0 , Smereka J, et al. Securing the airway patency by firefighters with the use of CombiTube. A pilot data. Disaster and Emergency Medicine Journal. 2018; 3(2): 46-50, doi: 10.5603/demj.2018.0011.

6. Ruetzler K, Madziala A, Madziala $M$, et al. Attitudes of firefighters towards the use of supraglottic airways devices. Am J Emerg Med. 2019 [Epub ahead of print], doi: 10.1016/j.ajem.2019.01.028, indexed in Pubmed: 30674429.

7. Scheidt S, Roessler PP, Pedrood S, et al. Influence of the trauma mechanism on cervical spine injuries. Unfallchirurg. 2019 [Epub ahead of print], doi: 10.1007/s00113-019-0622-z, indexed in Pubmed: 30840088.

8. Monsieurs KG, Nolan JP, Bossaert LL, et al. ERC Guidelines 2015 Writing Group. European Resuscitation Council Guidelines for Resuscitation 2015: Section 1. Executive summary. Resuscitation. 2015; 95: 1-80, doi: 10.1016/j.resuscitation.2015.07.038, indexed in Pubmed: 26477410.

9. Yeung J, Chilwan $M$, Field $R$, et al. The impact of airway management on quality of cardiopulmonary resuscitation: an observational study in patients during cardiac arrest. Resuscitation. 2014; 85(7): 898-904, doi: 10.1016/j.resuscitation.2014.02.018, indexed in Pubmed: 24594093.

10. Szarpak L, Kurowski A, et al. Alternative methods of airway management in children. Nowa Pediatria. 2014; 3: 92-96. 